\title{
TEKNOLOGI DIGITAL SEBAGAI MEDIA OBJEKTIFIKASI PEREMPUAN: KAJIAN KRITIS MEDIA SOSIAL
}

\section{Himmatul Khairah ${ }^{1}$ dan Shuri Mariasih Gietty Tambunan ${ }^{2}$}

\author{
${ }^{1}$ Fakultas Ilmu Pengetahuan Budaya, Universitas Indonesia Depok. \\ Email: himmatul.khairah@ui.ac.id \\ ${ }^{2}$ Fakultas Ilmu Pengetahuan Budaya, Universitas Indonesia Depok. \\ Email: shuri.mariasih@ui.ac.id
}

Masuk : 15-04-2019, revisi: 25-11-2019 diterima untuk diterbitkan : 26-11-2019

\begin{abstract}
ABSTRAK
Sebagai bagian dari perkembangan teknologi digital yang sangat dinamis, media sosial dapat berfungsi sebagai media pemberdayaan perempuan atau media untuk meningkatkan kesadaran (awareness) terhadap isu-isu gender. Akan tetapi, dalam kenyataannya, media sosial justru dipakai sebagai alat pelanggeng dominasi ideologi patriarki yang memosisikan perempuan sebagai obyek atau pihak yang lebih inferior. Kajian kritis terhadap media sosial melalui pendekatan multi disiplin seperti yang dilakukan dalam penelitian ini dengan menggunakan metode digital ethnography harus terus dikembangkan agar penelitian akademis dapat membongkar ideologi dominan dalam praktik budaya yang terjadi di media sosial. Penelitian ini menganalisis bagaimana media sosial Instagram digunakan oleh penggunanya, dalam hal ini seorang public figure, yang memiliki follower dalam jumlah banyak melalui akun@phtfcl, untuk mengkonstruksi imaji laki-laki maskulin sebagai individu yang sukses karena memiliki kekayaan yang dapat digunakan untuk mendapatkan perempuan 'ideal'. Pemikiran dasar penelitian ini adalah bagaimana objektifikasi perempuan terutama dalam media sosial sangat terkait dengan status sosial perempuan di dunia 'nyata.' Inilah yang kemudian menjadi signikansi utama mengapa media sosial harus selalu dipermasalahkan kompleksitasnya. Permasalahan utama adalah bagaimana PHT mengkonstruksi pemaknaan dominan atas dirinya sebagai bagian dari konstruksi dominan mengenai maskulinitas yang memosisikan perempuan sebagai obyek. Temuan penelitian menunjukkan objektifikasi perempuan sebagai bentuk pelanggengan budaya patriarki yang direproduksi secara berkesinambungan oleh media sosial. Akan tetapi, peneliti juga menemukan adanya dinamika afirmasi dan kontestasi oleh warganet sebagai bagian dari masyarakat jejaring yang secara aktif menunjukkan agensinya dalam memaknai objektifikasi tersebut.
\end{abstract}

Kata Kunci: media sosial, objektifikasi perempuan, maskulinitas, relasi kuasa

\begin{abstract}
As part of the dynamic development of digital technology, social media serves as a medium for women empowerment or to increase awareness of gender issues. However, in reality, social media is often used as a tool to perpetuate the domination of patriarchal ideology that positions women as more inferior objects or party. Critical studies of social media through a multidisciplinary approach as conducted in this study using digital ethnography methods must continue to be developed in order for academic research to dismantle the dominant ideology in cultural practices that occur in social media. This study analyze how Instagram social media is used, in this case, by a public figure with a large number of followers through the @ phtfcl account, to construct the image of masculine men as successful individuals because they have wealth that can be used to get 'ideal' women. The basic thinking of this research is how the objectification of women, especially in social media is closely related to the social status of women in the 'real' world. This is then the main significance of why social media must always be questioned about its complexity. The main problem is how PHT constructs the dominant meaning of himself as part of the dominant construction of masculinity that positions women as objects. Research findings show objectification of women as a form of perpetuating patriarchal culture that is reproduced on an ongoing basis by social media. However, researchers also found the dynamics of affirmation and contestation by citizens as part of a networked society that actively shows its agency in interpreting said objectification.
\end{abstract}

Keywords: social media, objectification of women, masculinity, power relations 


\section{PENDAHULUAN \\ Latar Belakang}

Media sosial merupakan salah satu dampak dari perkembangan teknologi digital yang menjadikan intensitas penyebaran informasi dan terbukanya ruang komunikasi semakin tinggi dan cenderung tidak bisa dikontrol. Sebagai ruang publik yang memfasilitasi diskusi antar kelompok, media sosial banyak digunakan untuk aktifisme sosial. Dalam konteks feminisme, aktifisme di ruang digital: “... became a form of empowerment, a way to exert control over one's personhood and identity, while gaining a sense of being able to do something in the face of a patriarchal hierarchy and an authoritarian state" (Radsch \& Khamis, 2013, 883). Dengan kata lain, perkembangan teknologi digital telah menjadi sarana pemberdayaan ketika perempuan diberdayakan untuk berstrategi ketika menghadapi hirarki sosial dalam patriarki dan otoritas negara. Selain itu, media sosial juga digunakan oleh perempuan untuk merepresentasikan diri secara strategis dalam menghadapi ideologi patriarki atau apa yang disebut oleh Murray (2005) sebagai "self-imaging strategies." Dalam penelitiannya, Murray melihat bagaimana praktik budaya selfie yang banyak dikritik sebagai bentuk narsisisme di dunia maya justru dapat menjadi sarana pemberdayaan perempuan atau bahkan sebagai "aesthetic form of resistance."

Akan tetapi, di lain sisi, ketika media sosial membuka ruang untuk melakukan aktifisme yang dapat mengkontestasi dominasi ideologi patriarki, ruang digital tersebut juga dapat menjadi medium objektifikasi perempuan. Media dalam perkembangannya memosisikan perempuan sebagai obyek seperti yang dijelaskan oleh Berberick (2010): "The representation of women in the media has always been exploitative. It has, throughout the years, reduced women to being nothing more than objects to be won, prizes to be shown off, and playthings to be abused" (2). Imaji perempuan dalam media biasanya diposisikan sebagai obyek atau hadiah yang dapat dieksploitasi. Dobson (2016) berargumen bahwa objektifikasi perempuan terutama dalam media sosial sangat terkait dengan status sosial perempuan di dunia 'nyata.' Maka dari itu, kajian kritis terhadap media sosial untuk melihat bagaimana objektifikasi dilakukan menjadi penting untuk membongkar dan pada akhirnya mengkontestasi dominasi ideologi yang melatar belakangi praktik budaya tersebut.

Penelitian ini memilih akun Instagram PHT, seorang wirausahawan [pekerjaan disamarkan red.] dan public figure di Indonesia, sebagai studi kasus karena unggahan-unggahannya yang memosisikan perempuan sebagai obyek. Akun Instagram PHT dengan username@phtfcl berisi 6.362 unggahan mengenai informasi tentang dirinya sendiri, dan aktivitas pekerjaan yang beliau lakukan sehari-hari. Selain konten unggahan seperti ini, di akun Instagram tersebut juga terdapat banyak unggahan berisi foto atau video dengan dialog singkat yang dilakukan oleh PHT dengan beberapa perempuan. Dalam hal ini, foto dan video yang ditampilkan dalam akun Instagram tersebut kebanyakan juga mencerminkan keberhasilan beliau sebagai seorang yang sukses dan public figure terkenal. Hal itu dapat dilihat melalui unggahan barang-barang mewah yang terpajang di akun beliau. Peneliti melihat unggahan-unggahan yang berisi foto dan video PHT dengan perempuan sebagai bentuk objektifikasi perempuan. Permasalahan yang akan dieksplorasi dalam penelitian ini adalah bagaimana PHT mengkonstruksi pemaknaan dominan atas dirinya sebagai artikulasi hegemonic masculinity (Connell \& Messerschmidt, 2005) yang memosisikan perempuan sebagai “... objects to be won, prizes to be shown off ...” (Berberick, 2010, 2). Analisis studi kasus ini bertujuan untuk menganalisis praktik objektifikasi yang dilakukan seorang public figure dalam kaitannya dengan pemosisian teknologi digital yang, apabila penggunaannya tidak dikritisi, dapat melanggengkan relasi kuasa yang tidak seimbang dalam ideologi patriarki. 


\section{METODE PENELITIAN}

Penelitian ini menggunakan metode digital ethnography yang memperlakukan media sosial sebagai ranah atau wilayah yang diteliti sama halnya seperti yang dilakukan penelitian ketika turun lapangan (field work). Lapangan atau field di studi kasus ini adalah media sosial Instagram atau lebih spesifik lagi, akun Instagram @phtfcl.

The everyday life of the social media ethnographer involves living part of one's life on the internet, keeping up to date with and participating and collaborating in social media discussions. This is not simply a virtual experience but is connected to the material world in important ways. It involves charting out and living through the ethnographic place of the fieldsite, which is a sensorily embodied, rather than 'virtual' experience ... (Postill \& \& Pink, 2012, 128).

Dalam digital ethnography terutama ketika melakukan kajian media sosial, peneliti melakukan penelitian terhadap subyek penelitian dengan mengikuti kegiatan sehari-harinya atau berpartisipasi dalam diskusi misalnya dengan mengomentari sebuah unggahan sama halnya seperti ketika seorang etnografer turun ke lapangan dan mengikuti kegiatan subyek penelitiannya. Untuk itu, peneliti melakukan observasi terhadap setiap unggahan dan kemudian mengkategorisasikan unggahan yang muncul secara berkala berdasarkan kata kunci: unggahan mengenai pekerjaannya, unggahan personal mengenai dirinya sendiri dan unggahan yang berisi objektifikasi perempuan. Setelah mengkategorisasikan data, peneliti melakukan kajian tekstual terhadap isi unggahan baik elemen visual maupun kata-kata yang dipakai di dalam caption.

\section{HASIL DAN PEMBAHASAN}

Connell dan Messerschmidt (2005) berargumen bahwa maskulinitas dikonstruksikan melalui praktik representasi di media mainstream yang memosisikan laki-laki untuk mengafirmasi konstruksi tersebut. "It is men's and boys' practical relationships to collective images or models of masculinity, rather than simple reflections of them, that is central to understanding ..." (Connell \& Messerschmidt, 2005, 841). Imaji-imaji yang secara kolektif didiseminasikan dalam media mengenai bagaimana laki-laki harus bertingkah laku terutama dalam kaitannya dengan hubungan personal dengan perempuan menunjukkan apa yang disebut sebagai karakteristik ideal yang maskulin atau "actual characteristics of 'being a man". Dalam hal ini, hegemonic masculinity mengkonstruksi pemaknaan bahwa laki-laki yang sukses adalah laki-laki yang dapat menafkahi keluarga dengan penghasilan yang besar yang kemudian menjadi modal untuk mendapatkan perempuan. Hal inilah yang diinterpretasikan peneliti ketika melakukan kajian kritis terhadap unggahan-unggahan PHT dalam akun Instagramnya.

Representasi diri PHT menunjukkan representasi diri yang ingin menekankan identitas sebagai wirausaha laki-laki yang sukses dan seorang publik figur yang terkenal. Penanda-penanda yang dibaca oleh peneliti dapat ditemukan di unggahan PHT terkait barang-barang mewah seperti cincin berlian dan mobil mewah disertai dengan narasi-narasi dalam caption foto atau video yang mempertegas bahwa kesuksesan seorang laki-laki terukur dari materi yang diperoleh.

Melalui dua unggahan di atas dapat dilihat bahwa PHT berusaha memunculkan identitas sebagai wirausaha yang berlimpah harta dan hal itupun kemudian digunakan untuk dapat mengobjektifikasi perempuan. Penulis menginterpretasi caption yang ada di salah satu foto yang menunjukkan foto pribadi sebagai laki-laki yang sukses dengan menggunakan jas dan cincin serta jam mahal untuk menunjukkan kemapanan sebagai seorang laki-laki yang kemudian dipertegas dengan caption 'Hai Girls' yang ditujukan langsung kepada perempuan. Kemudian 
pada foto yang kedua terlihat bagaimana PHT berpose dengan menaruh tangannya di pundak seorang gadis dan di sampingnya terdapat salah satu mobil mewah miliknya. Foto itu merupakan satu dari banyak contoh gaya yang selalu dilakukan oleh PHT ketika berfoto dengan seorang wanita. Mempelajari foto lainnya, peneliti menginterpretasikan PHT ingin menunjukkan melalui simbol mobil disampingnya sebagai wirausaha yang sukses dan bisa melakukan apapun kepada perempuan manapun.

Unggahan PHT yang memosisikan dirinya sebagai laki-laki yang "berhasil" dan memperoleh kesuksesan dengan menunjukkan harta kekayaannya dapat diinterpretasi sebagai representasi hegemonic masculinity.

Masculinity refers to the socially produced but embodied ways of being male. Its manifestations include manners of speech, behavior, gestures, social interaction, a division of tasks "proper" to men and women, and an overall narrative that positions it as superior to its perceived antithesis, femininity. The discourse of masculinity as a dominant and superior gender position is produced at a number of sites and has specific consequences for women as well as those men who may not fit into the dominant and valorized models of masculinity (Srivastava, 2015, 332).

Narasi dominan mengenai maskulinitas yang kemudian terhegemoni di dalam masyarakat menunjukkan bagaimana laki-laki harus memperoleh kesuksesan supaya selalu dapat membedakan diri sebagai pihak yang lebih superior dibandingkan antitesisnya: femininitas. Selain menekankan pada harta yang dimiliki, melalui gambaran sebuah mobil, PHT sedang menggandeng seorang perempuan cantik sebagai bagian dari simbolisasi kesuksesan dan maskulinitasnya.

Selain foto, dalam akun Instagram PHT, peneliti menemukan unggahan dalam bentuk video yang berisi interaksi yang dilakukan oleh PHT dengan beberapa perempuan 'ideal' yang dapat dibaca sebagai bentuk objektifikasi terhadap perempuan. Hal itu dipertegas dengan narasi yang dibangun oleh PHT sendiri melalui dialog dalam video serta caption yang terdapat dalam unggahan tersebut. Peneliti melihat bahwa objektifikasi digunakan untuk menegaskan identitas PHT sebagai laki-laki yang sukses dan lebih superior dari perempuan. Dalam hal ini, komentarkomentar pengikut dalam akun tersebut juga banyak yang berbicara mengenai lelaki kaya yang kemudian sah-sah saja melakukan apapun terhadap para perempuan. Komentar di unggahanunggahan tersebut juga banyak yang mengafirmasi bahwa kesuksesan PHT sebagai wirausaha kaya raya lah yang memberikan legitimasi bagi dirinya untuk mendapatkan perempuan yang ada dalam unggahannya. Sebagai contoh, @ pndl dalam unggahan di @ phtfcl pada tanggal 10 Maret 2019 memberikan komentar "Tipnya kerja keras, kumpulin duit yg banyak, gak usah dirayu cewek datang sendiri." Komentar-komentar senada juga dapat ditemukan di unggahan lainnya yang menunjukkan afirmasi terhadap konstruksi maskulinitas dan objektfikasi perempuan dalam akun Instagram PHT.

Untuk mendukung argumen tersebut, peneliti akan mengambil 1 contoh unggahan untuk dianalisis baik dalam unggahannya maupun komentar-komentar yang ada di unggahan tersebut. Unggahan berikut menunjukkan PHT dengan tangannya yg diletakkan di atas bahu seorang perempuan. Telunjuk kanan PHT dengan posisi menunjuk menempel di pipi kiri perempuan tersebut yang sedang tersenyum ke arah kamera. Posisi tubuh PHT dan perempuan yang ada dalam unggahan menunjukkan relasi kuasa yang tidak seimbang yaitu perempuan yang lebih inferior yang dapat dimaknai dari posisi tangan PHT. 
Berdasarkan gambaran di atas, peneliti menginterpretasi bagaimana PHT melakukan objektifikasi terhadap perempuan melalui foto yang beliau unggah dengan perempuan di akun Instagramnya. Hal itu pun senada dengan komentar-komentar yang diberikan warganet sebagai bentuk respon terhadap foto tersebut. Sebagian warganet merasa PHT sebagai seorang laki-laki dalam hal ini telah mengobjektifikasi perempuan. Mereka mengkontestasi objektifikasi yang dilakukan PHT ketika menyentuh bagian tubuh dari perempuan dan wajah perempuan yang menurut warganet merasa tidak nyaman dengan posisi tangan PHT. Warganet juga ada yang mencela PHT karena dianggap memosisikan diri sebagai seorang laki-laki kaya yang kemudian bebas memperlakukan wanita perempuan seperti demikian.

\section{KESIMPULAN DAN SARAN}

Melalui akun Instagramnya, PHT merepresentasikan dirinya sebagai simbolisasi maskulinitas yang hegemonik dan lebih superior dibandingkan perempuan yang sering muncul di unggahannya. Melalui representasi dirinya sebagai wirausaha sukses dan publik figur yang terkenal, PHT memosisikan perempuan sebagai obyek atau bahkan hadiah yang ia menangkan melalui materi dan kesuksesannya. Selain itu, identitas tersebut juga dipertegas dengan unggahan video dan foto dengan banyak perempuan yang kemudian diafirmasi dalam komentar unggahan. Dalam hal ini objektifikasi tersebut bermain akibat adanya kesenjangan relasi kuasa dimana PHT menganggap dirinya lebih superior sebagai laki-laki sukses dan kaya sehingga dapat mengobjektifikasi perempuan yang dia temui atau dia ajak untuk berfoto. Hal tersebut terlihat dari unggahan berupa foto dan video yang terdapat dalam Instagram tersebut dimana PHT tidak jarang menyentuh perempuan-perempuan yang terdapat dalam video maupun foto di unggahan instagramnya. Perempuan-perempuan yang terdapat dalam Instagramnya sebenarnya sangat beragam dan datang dari jenis profesi atau pekerjaan yang beragam juga seperti asisten pribadi, petugas bandara, pramugari, advokat muda hingga para artis. Akan tetapi, profesi apapun tampaknya masih direpresentasikan sebagai pihak yang lebih inferior dari dirinya. Hal senada pun ditunjukkan melalui komentar-komentar netizen yang berpendapat bahwa PHT sebagai pria yang kaya bergelimang harta kemudian dapat melakukan apapun kepada perempuan termasuk menyentuh perempuan-perempuan tersebut. Objektifikasi itu kemudian dilihat oleh peneliti sebagai bentuk pelanggengan budaya patriarki yang direproduksi secara berkesinambungan oleh media sosial.

Kajian kritis terhadap media sosial dalam kaitannya dengan objektifikasi perempuan dapat menjadi ruang diskusi ilmiah maupun diskusi sosial dengan masyarakat luas untuk membongkar praktik pelanggengan ideologi patriarki. Dari hasil analisis ini, peneliti menyimpulkan bahwa apabila hasil kajian kritis diseminasikan ke masyarakat umum, kesadaran (awareness) bahwa maskulinitas tidak selalu harus didasari objektifikasi terhadap perempuan dapat mulai dibangun. Atau dengan kata lain, menjadi laki-laki tidak selalu harus diasosiasikan dengan posisi superior dan inferior antara laki-laki dan perempuan. Media sosial, seperti dijelaskan di latar belakang, justru dapat menjadi media pemberdayaan walaupun dalam studi kasus ini, sebelum menjadi media pemberdayaan, media sosial menjadi ruang penyampaian ekspresi misalnya melalui komentar warganet yang mengkontestasi narasi maskulinitas PHT.

\section{Ucapan Terima Kasih (Acknowledgement)}

Melalui tulisan ini saya ingin mengucapkan terima kasih kepada pihak-pihak yang telah memberikan masukan serta ide-ide terkait penelitian mengenai media sosial. 


\section{REFERENSI}

Connell, R. W., \& Messerschmidt, J. W. (2005). Hegemonic masculinity: Rethinking the concept. Gender \& society, 19(6), 829-859.

Dobson, A. S. (2016). Postfeminist digital cultures: Femininity, social media, and selfrepresentation. New York: Palgrave Macmillan.

Berberick, S. N. (2010). The objectification of women in mass media: Female self-image in misogynist culture. The New York Sociologist, 5(1), 1-15.

Murray, D. C. (2015). Notes to self: the visual culture of selfies in the age of social media. Consumption Markets \& Culture, 18(6), 490-516.

Postill, J., \& Pink, S. (2012). Social media ethnography: The digital researcher in a messy web. Media International Australia, 145(1), 123-134.

Radsch, C. C., \& Khamis, S. (2013). In their own voice: Technologically mediated empowerment and transformation among young Arab women. Feminist Media Studies, 13(5), 881-890.

Srivastava, S. (2015). Modi-masculinity: Media, manhood, and "traditions" in a time of consumerism. Television \& New Media, 16(4), 331-338.

Zulkodri, (2018). Kembali PHT pamer. Diunduh dari http://bangka.tribunnews.com/_/kembaliPHT-pamer-.... 